\title{
Paralelos entre a curadoria de conteúdo em redes sociais e a gestão do conhecimento
}

Parallels between content curation in social networks and knowledge management

Lucas Gordon ${ }^{1}$ 


\section{Resumo}

Partimos para o novo mundo, aquele em que muitas vezes o virtual é muito mais importante e relevante para a sociedade que o próprio ambiente físico. Nesse cenário, tudo se resume a dados e informações assimilados e geridos, eficientemente ou não. $O$ design da gestão dessa informação já ocorre no âmbito do conhecimento explícito, ou seja, são dados e informações que já estão consolidados nos veículos de comunicação, como o livro impresso, fotografia e até a Internet. Em paralelo com essa administração da informação, o crivo, a seleção e a recomendação do conteúdo jogam um papel de igual importância no navegar por entre o imenso mar de dados.

Tanto na gestão do conhecimento como na curadoria de conteúdo, a complexidade está na inserção do conhecimento tácito no universo, ou seja, um ou mais indivíduos da organização fornecem suas experiências, crenças, sentimentos, vivências, valores, crítica, etc. Este trabalho quer encontrar paralelos e pontos convergentes entre curadoria de conteúdo e gestão do conhecimento, descobrindo formas de potencializar as práticas de design da gestão e curadoria consolidadas.

Palavras-Chave: Curadoria de conteúdo, design de sistemas, gestão do conhecimento, redes sociais, informação.

\section{Abstract}

We are heading for a new world, one in which the virtual is often much important and relevant to society than the actual physical environment. In this scenario, it all comes down to data and information assimilated and managed efficiently or not. The management of this information is already in explicit knowledge, it means data and information that are already well established in the media, like printed books, TV or even the Internet. In parallel with this information management, the screen, the selection and recommendation of content play an equally important role in navigating through the vast sea of data.

Both in knowledge management as in the content curation, the complexity lays in the integration of tacit knowledge in the universe, in other words, one or more individuals in the organization providing their experiences, beliefs, feelings, experiences, values, critical etc. This paper wants to find parallels and converging points between content curation and knowledge management, finding ways to enhance management practices and curatorial statements.

Keywords: Curated content, system design, knowledge management, social networking, information.

ISSN: 1808-3129

${ }^{1}$ Lucas Gordon

Brasil

psylucas@gmail.com 


\section{Introdução}

A internet se tornou a primeira opção para quem quer ou precisa encontrar algo, seja uma informação, um objeto de desejo, uma rota ou até mesmo um amigo pra conversar. Ela tem de tudo e uma simples busca leva sempre a algum resultado, uma possível solução para o problema, possível. Esse navegar impreciso, caótico, à primeira vista não obedece a hierarquias, deixa ao leitor o livre arbítrio, dá a ele o comando sobre a rota que vai traçar. E, quando assume o poder da escolha, ele é seu próprio editor.

Fora da rede, as escolhas são mais limitadas. No mercado, por exemplo, antes de fazer sua opção de compra, o sujeito se depara com escolhas feitas previamente por quem produziu um determinado bem. Há nisso uma tentativa de encontrar um padrão que aproxime ou ajuste o bem ao gosto ou à necessidade da clientela. $\mathrm{O}$ desejo do consumidor está quase sempre à mercê da escolha prévia de um especialista ou submetido a pacotes que pretendem representar uma média de mercado. Ou seja, por trás de um balcão também há um editor.

Antes da internet, o acesso à informação seguia por esse caminho. Ao comprar uma revista ou um jornal, se adquiria um pacote. $O$ interesse poderia ser específico, mas, era-se obrigado a levar o pacote completo. Havia somente duas opções: era tudo ou nada.

A internet inverteu a lógica. Ao fragmentar todo o seu conteúdo e criar laços entre os fragmentos, a web tornou a ideia do pacote obsoleta. O leitor pode determinar sua experiência de navegação, como se fosse o único consumidor de toda a informação disponível. Criando um novo ecossistema mídiático misto: contendo os meios de comunicação analógicos, surgidos a partir das concepções econômicas da Revolução Industrial, e as redes digitais conectadas, que possuem conexões topológicas descentralizadas e de baixa hierarquia, fornecendo novas possibilidades de consumo de conteúdo. As tecnologias digitais conectadas ampliaram o espectro de possibilidades no campo da comunicação social. Passamos, em um curto espaço de tempo, da era da escassez da informação (que durou centenas de anos) para a era do Big Data.

Nessa estrutura informacional emergem possibilidades de estabelecer diferentes tipos de relação entre o emissor de conteúdo informativo de relevância social e a sua audiência. Ou seja, a relevância é a principal razão para que as pessoas utilizem as Tecnologias de Informação nas suas atividades de informação. Na Web coexistem dois complexos sistemas informativos interagindo, um construído através dos sistemas computacionais e o outro que movimenta todo o aparato tecnológico: a sociedade (o ser humano interagindo).

Nesse cenário, fica claro que há uma nova economia se estabelecendo no mundo, resultante da aplicação de conhecimentos sem precedentes ao processo de criação de riqueza, o autor dessa afirmação é o futurista, Alvin Toffler (1980, pg 116). Para ele a próxima economia nao é orientada pelo produto, mas por serviços: uma economia baseada em redes sociais e tecnológicas, em que as pessoas, produtos e lugares interagem para obter um valor de reconhecimento comum. 
O presente estudo propõe um aprofundamento dos paralelos entre dois conceitos complementares: a curadoria de conteúdo e a gestão do conhecimento, já que se ao primeiro cabe o rol de qualificar dados e informações, ao segundo compete o papel de gerir e tornar disponíveis e úteis os resultados do primeiro.

\section{Gestão do Conhecimento}

Provavelmente originada graças internet, hoje muito se ouve a expressão "sociedade da informação", já que a civilização ocidental foi sendo caracterizada pela economia alicerçada na informação e na telemática, ou seja, dados, comunicação, telecomunicação e tecnologias da informação. A informação, aqui entendida como matéria-prima, como insumo básico do processo, a comunicação/telecomunicação, entendida como meio/veículo de disseminação/distribuição, e as tecnologias da informação, entendidas como infraestrutura de armazenagem, processamento e acesso.

Para Chomsky (2008, pg. 44) a sociedade da informação e sua relação com a economia de um país se dá através de uma superestrutura de comunicação, apoiada em tecnologias da informação e, o mais importante, o conhecimento, sua geração, armazenamento e disseminação, o que se denomina atualmente de "nova economia", é a associação da informação ao conhecimento, sua conectividade e apropriação econômica e social. Isso exige dos diferentes segmentos econômicos uma mudança significativa no processo produtivo e inovativo.

O desafio está na percepção das organizações de que a nova economia está baseada no conhecimento e deve ser visto como uma atividade, um serviço, um produto e um processo (Ghani, 2009, pg. 14).

Segundo Ghani (2009, pg. 20), o conhecimento pode ser definido como dados ou informações organizados de forma útil para um determinado fim. Na gestão do conhecimento, o objetivo é aproveitar de forma ótima os conhecimentos existentes, desenvolvendo-os e transformando-os em novos produtos, processos e campos da atividade econômica. Dessa forma, o capital intelectual, semelhante ao capital financeiro, deve aumentar, e elevar o valor da organização. Para tanto, a gestão abrange clientes, fornecedores, sócios e outros usuários externos, significando uma abertura simultânea para fora e para dentro da empresa (NORTH, 2010, pg. 27).

A gestão do conhecimento, deste modo, utiliza conceitos, técnicas, métodos e modelos de diferentes disciplinas, tais como design, a psicologia cognitiva, ciência da informação, ciências da computação, engenharias e administração, para captar, reter, disseminar e estimular a criação de conhecimento tácito nas organizações. Todavia, após a implantação de novas práticas, as organizações também incorporam em seus processos novos conceitos envolvendo pessoas, de modo que sejam alcançados os objetivos estratégicos e cumprida a missão institucional. Por exemplo, técnicas de benchmarking e medição devem ser adaptadas, pois de forma coerente contribuem para os objetivos considerando o tipo e tamanho da empresa, o mercado, a cultura organizacional e demais aspectos relevantes (VARVAKIS et.al, 2009, pg. 420).

Por ser um assunto contemporâneo e de grande relevância no cenário organizacional, a gestão do conhecimento hoje conta com algumas práticas e proces- 
sos consolidados. Dentre as práticas citam-se Narrativas, Lições Aprendidas, Brainstorming, Redes Sociais e Repositórios de Conhecimento. Já os processos envolvem principalmente, a criação de conhecimento, transferência, disseminação, compartilhamento e proteção de conhecimento.

\section{Curadoria de Conteúdo}

Segundo Barcelos (BARCELOS, 2011, pg. 102), popularmente, o termo foi adotado para à área das artes, ocupando muitas vezes o terreno da crítica, a despeito de muitos especialistas. Ao curador, dono de sábio conhecimento sobre pintores, escultores e artistas visuais e, ainda, mestre no ofício de organizar exposições e bienais, coube a tarefa básica de credenciar obras, validá凶las por uma escolha legitimada e racional e, por fim, selecioná-las para um determinado público. Resumidamente, colocar à disposição do espectador/apreciador o que de melhor haveria em determinado estilo ou vertente.

Paralelamente, graças à internet, e por culpa dela também, para diversos profissionais hoje resulta lógico, e até necessário, recorrer à diversas fontes de informação para referênciar seus projetos. Lamentavelmente, desordenada e extensa, a carga de informação que a rede mundial de computadores, a chamada "web" oferece, dificulta o processo de obter conteúdo relevante para inspirar e balizar seus trabalhos. Perdese tempo e foco, já que o conhecimento válido se dilui em um mar de dados e buscas infrutíferas. São buscas que poderiam passar por uma analise prévia de seus conteúdos, gerando precedentes referenciais relevantes e que poderiam auxiliar e agilizar a criação de soluções e decisões para os distintos problemas de projeto. Exemplifica bem essa re-contextualização da curadoria a frase de Joaquim Fidalgo:

A especificidade do trabalho dos profissionais da informação poderá estar, futuramente, menos na revelação de notícias ou dados 'em primeira mão', e mais na interpretação e contextualização dessas notícias, bem como num serviço de sinalização e certificação que permita ao público orientar-se num ambiente cada vez mais inundado de fluxos informativos de todas as proveniências, onde será necessário saber 'navegar' distinguindo 'o trigo do joio' para fazer um percurso autónomo mas crítico. (FIDALGO, 2010, p.13)

Nessa necessidade e futuro se enquadra a figura da curadoria de conteúdo na web, como a ferramenta que aumenta drasticamente os níveis de eficiência e assertividade da navegação. Naturalmente, esse espaço, essa nova área de atuação oriunda da atual deficiência é percebida pelo mercado, e da sua competitividade, surgem ferramentas dentro da web para auxiliar e democratizar o processo de filtrar, categorizar e valorar dados, originando a expressão "curadoria de conteúdo web": o processo de pesquisar, contextualizar e organizar as informações de uma área específica. $O$ seguinte manifesto de Rohit Bhargava resume:

Num futuro próximo, os especialistas prevêem que o conteúdo na web dobrará a cada 72 horas. A análise separada de um algoritmo não será mais suficiente para encontrar o que estamos procurando. Para satisfazer a fome das pessoas por um grande conteúdo sobre qualquer assunto imaginável, haverá a necessidade de ter uma categoria nova de trabalho em linha individual. Alguém cujo trabalho não é 
para criar mais conteúdo, mas para dar sentido a todo o conteúdo que os outros estão criando. Para encontrar o melhor e mais relevante conteúdo e trazê-lo para frente. As pessoas que optarem por assumir esse papel serão conhecidos como curadores de conteúdo. O futuro da web social será impulsionado por esses curadores de conteúdo, que assumem a responsabilidade de coletar e compartilhar o melhor conteúdo on-line para outros consumirem e assumirem o papel de cidadãos editores, publicando compilações de grande valor de conteúdo criado por outros. Com o tempo, esses curadores trarão mais utilidade para a web. Ao fazer isso, eles vão ajudar a adicionar uma voz e ponto de vista de organizações e empresas que podem conectá-los aos clientes - a criação de um diálogo inteiramente novo com base em conteúdo valorizado não apenas mensagens de marketing da marca. (Rohit Bhargava, 2010, pg. 77).

\section{A web 2.0, as novas redes sociais e a curadoria}

Sistemas compartilhados na web, essencialmente caracterizados pela possibilidade de participação e intervenção dos sujeitos, possibilitando a interação de muitos para muitos, constituem a base do conceito de web 2.0. Conforme O'Reilly (2007, pg. 33), a web 2.0 é a rede como plataforma, abarcando todos os dispositivos conectados a ela. As aplicações web 2.0 são aquelas que utilizam as possibilidades dessa plataforma criando efeitos na rede através de uma "arquitetura de participação". Chama-se esse tipo de aplicação de "software social". Conforme Spyer (2007, p. 21), "o termo 'social software' é usado para se referir ao tipo de programa que produz ambientes de socialização pela internet, ele é que está por trás da colaboração online", como redes de relacionamento, blogs, micro blogs, wikis, compartilhamento de arquivos e outros.

Graças a web 2.0, as redes sociais tornaram-se a nova mídia, em cima da qual informação circula, é filtrada e repassada; conectada à conversação, onde é debatida, discutida e, assim, gera a possibilidade de novas formas de organização social baseadas em interesses das coletividades. Esses sites atingem novos potenciais com o advento de outras tecnologias, que aumentam a mobilidade do acesso às informações, como os celulares, tablets, smartphones e etc. Redes sociais passam a ser constituídas em fluxos informacionais, refletindo a era da conexão proposta por Manuel Castells (2003, pg. 13).

Quem jamais sonhou em ser um produtor de conteúdo ou, meramente, um distribuidor de informação, não escapa mais do título de emissor, quando antes tinha apenas o status de receptor. Nas redes sociais, qualquer pessoa pode ascender à posição de criador de conteúdo e a avalanche de informação já tem um preço: desordem, sobrecarga e, digamos, desinformação. É aí que entra em cena a figura do curador de conteúdo, termo que procura dar identidade ao recente papel de quem seleciona, organiza e distribui notícias, posts, pins e até tweets para um determinado público. 


\section{Paralelos e pontos de contato}

A tarefa de curadoria parece ser simples, mas requer planejamento. Antes de pensar em métricas e aguardar pela colaboração do usuário, o curador precisa ter bem claro o tipo de conteúdo que será importante para seu público. Portanto, é necessário conhecer a audiência, fazer pesquisas e sondagens para se tornar um filtro de referências. A exemplo de outras ações nas redes sociais em que se busca fidelidade e boa reputação, a curadoria se legitima por oferecer um serviço, informação relevante e que faz a diferença entre a grande quantidade de informações. Sua validade portanto se dá em uma sequência de resultados bem recebidos por seus "usuários/ clientes", que outorgam valor a sua atuação individual. Esse é o approach tradicional do curador; um erudito que proporciona atalhos de conhecimento sobre determinada área.

Longe de julgar a razão de ser da sua função, hoje indivíduos e organizações se deparam com a realidade de ter de atingir um universo grande e intrincado de receptores (desde clientes a internautas, pacientes, ouvintes, leitores, virtualmente qualquer um que o emissor deseje atingir). Essa variedade demanda uma curadoria, não mais individualizada, mas feita por grupos que podem ser os próprios receptores, isto é, grupos de contextualização e valorização de conteúdos que balizam e filtram conhecimentos.

Em um paralelo entre a gestão do conhecimento e a curadoria de conteúdo, na curadoria de conteúdo pela web, os novos "curadores" se encontram em redes sociais e comunidades online especificamente voltadas a identificar o que é interessante e atrativo para o grupo, gerindo a informação. Por exemplo, na rede social Pinterest, o volume de compartilhamentos que um determinado conteúdo obtêm, determina um certo nível de aceitação e popularidade, desta forma a curadoria de conteúdo ocorre no e pelo grupo. O site é uma espécie de "catalogo virtual" onde as pessoas podem coletar, organizar e compartilhar conteúdos, principalmente, imagens e vídeos. Como em um painel ou mural, os "pins" (conteúdos que os usuários colocam em seus painéis) podem ser compartilhados entre usuários.

Outra situação em que se encontram os resultados de um paralelo entre a gestão do conhecimento e a curadoria de conteúdo é o site denominado Zite. Em março de 2011, o Zite inaugurou uma nova geração de aplicativos agregadores. Ele tinha uma interface simples, design enxuto e era configurado para colher links da rede de relacionamentos do usuário e exibir no aplicativo informações classificadas por temas selecionados previamente pelo leitor. A partir da configuração inicial, havia uma sofisticada engenharia que tratava a informação antes dela ser exibida nas telas.

Com a ajuda de um mecanismo de busca e curadoria contextual, as urls (Localizador-Padrão de Recursos) compartilhadas nas suas redes de relacionamento na web começavam a ser coletadas pelo Zite e a elas eram associadas uma série de metadados que ajudam a classificar os conteúdos. Dessa safra, o sistema descarta o que é lixo e, em seguida, associava as urls aos usuários que as compartilharam. Cada usuário tem sua reputação medida, considerando número de seguidores e o nível de compartilhamento que seus posts alcançam na rede. O sistema combina, então, as 
reputações dos usuários que compartilharam o link e cria uma espécie de ranking de urls. As melhores classificadas podem ser exibidas na tela do usuário, desde que atinjam uma pontuação mínima, um valor que define o interesse que cada leitor terá pelo tema.

Já na tela do Zite, o sistema aprende com a experiência do usuário e vai redefinindo os critérios de exibição a partir dela. Ele mapeia o conteúdo e diferencia o que o leitor acessou, o que compartilhou, o que guardou para ler mais tarde e o que deixou de clicar para entender mais precisamente o interesse do usuário. Além disso, a cada link acessado, o leitor pode informar ao sistema se o conteúdo foi relevante ou não e selecionar numa lista de tags associadas ao conteúdo os temas e as fontes que o Zite deve considerar como de seu interesse.

A personalização melhora continuamente a oferta de conteúdo. Foi por entender a essência da internet que o Zite se transformou numa espécie de browser inteligente. Aliou a busca exata, a gestão adequada do conhecimento à obtenção do conteúdo adequado, resultando no fascínio da descoberta. Prova do seu sucesso, em agosto de 2011, cinco meses depois de lançado, o Zite foi comprado pela CNN (conglomerado internacional de notícias). 


\section{Conclusões}

Desde a década de 1990, a "Gestão do Conhecimento" se tornou o avant-garde dos processos de gestão. Os pesquisadores, consultores e especialistas desta área incentivavam as empresas a considerarem a criação do conhecimento como uma fonte de vantagem competitiva, visando à construção de um ambiente de aprendizado para preencher as demandas de uma sociedade do conhecimento pós-industrial.

Neste sentido e como visto no presente trabalho, entidades inovadoras ou indivíduos vanguardistas identificaram oportunidades de melhorar métodos de curadoria de conteúdo com gestão do conhecimento através de plataformas digitais. Geralmente, essas propostas surgem em organizações de inovação e tecnologia, que possuem no aprendizado colaborativo, sua essência.

A chance de sucesso também é maior nas organizações que possuem, em sua maioria, funções realizadas estritamente no computador, já que, muito além das redes sociais, o ambiente virtual hoje está cada vez mais populado por grupos de profissionais de mesma área ou envolvidos em projetos comuns, que produzem informação a todo instante, construindo o "conhecimento coletivo organizacional" enquanto trabalham. Esse conhecimento informal é a materialização de uma nova forma de trabalhar, uma nova techne que pode estar sendo criada pelo grupo, cabendo registrar momentos, descrever e hierarquizar seu valor e gerenciar as informações que mantêm essas pessoas conectadas. 


\section{Referências bibliográficas}

BHARGAVA, R., Personality Not Included. New York: The New Press, 2010.

BRAMBILLA, Ana. Para entender as mídias sociais. v. 2, Salvador: Ed.VNI, 2012. Disponível em: http://paraentenderasmidiassociaais.blogspot.com.br/2012/03download-do-ebook-para-entender-as.html

CASTELLS, Manuel. A sociedade em rede. 7. ed. rev. e ampl. São Paulo: Paz e Terra, 2003b. v. 1.

CHOMSKY, Noam. Linguagem e responsabilidade. São Paulo: JSN Editora, 2007. On language: Chomsky's classic works. Language and Responsibility and Reflections on Language. New York: The New Press, 1998.

CYBIS, Walter de Abreu. Engenharia de Usabilidade: Uma abordagem Ergonômica. Labiutil: Florianópolis, 2003. Disponível em: http://www.labiutil.inf.ufsc.br/Apostila_nvVersao.pdf

DIAZ, A., Isakiwitz, T., Maiorana, V. e Gilabert, G. RMC: A Tool to Design WWW Applications. In: Proc. Fourth Int. WWW Conf. Boston, 1995. pp. 11-14.

FIDALGO, J., (2009). A critical overview on optimal experimental designs. Boletin de Estadística e Investigación Operativa, 25(1): 14-21.

GARZOTTO, F., Modeling-by-Patterns of Web Applications. In: Proc. International Workshop on the World Wide Web and Conceptual Modeling, WWW CM'99, Paris, Novembro, 1999.

GHANI, S. R. (2009); “Knowledge Management: Tools and Techniques”. Journal of Library \& Information Technology, Vol. 29, No. 6.

GORDHAMER, S.: 4 Ways social media is changing business. Mashable.com, http://mashable.com/2009/09/22/social-media-business (2009)

ISO (1997). ISO 9241-11: Ergonomic requirements for office work with visual display terminals (VDTs). Part 11 - Guidelines for specifying and measuring usability. Gènève: International Organisation for Standardisation.

KRUG, Steve. Não me Faça Pensar. São Paulo: Market Books, 2001.

LIMEIRA, Tania M. Vidigal. E-Marketing. O marketing na Internet com casos brasileiros. São Paulo: Saraiva, 2003. 
NIELSEN, J., Usability Engineering, Academic Press, New York, 1993.

NIELSEN, J.: Usability Testing. Salvendy, G. (ed.): Handbook of Human Factors and Ergonomics. 2nd edition. New York, NY: John Wiley \& Sons. 1997.

NIELSEN, J.: Test With 5 Users. Alertbox, March 19, 2000

NIELSEN, Jackob. Projetando Websites. Designing Web Usability. Rio de Janeiro: Campus, 2000.

NORTH, Klaus. Gestão do conhecimento: um guia prático rumo à empresa inteligente. Rio de Janeiro: Qualitymark, 2010. p. 4.

O'REILLY, Tim. What Is Web 2.0 - Design Patterns and Business Models for the Next Generation of Software. O'Reilly Publishing, 2005.

PINHO, J.B. Jornalismo na Internet: planejamento e produção da informação on line. São Paulo: Summus, 2003.

PRESSMAN, Roger S. Engenharia de Software. São Paulo: Makron Books, 1995.

SCHWABE, D.; ROSSI, G.:, An Object Oriented Approach to Web-Based Application Design, Theory and Practice of Object Systems 4(4), 1998. Wiley and Sons, New York.

SCHWABE, D.; PONTES, R. A.; Moura, I.; OOHDM-Web: An Environment for Implementation of Hypermedia Applications in the WWW, SigWEB Newsletter, Vol. 8, \#2, Junho de 1999.

SPYER, Juliano. Conectado: o que a internet fez com você e o que você pode fazer com ela. Rio de Janeiro: Jorge Zahar, 2007. 254 p.

TOFLER, Alvin. A terceira onda. 16. ed. Rio de Janeiro: Record, 1980.

VARVAKIS, G.J. Maldonado, M. U.; Dias, N. (2009); “Innovation Management Benchmarking in Brazilian Technology-based Small and Medium Enterprises". Espacios [online] vol. 30 (2). [citado 16 agosto 2011] p.16-18. Disponível em: http://www. revistaespacios.com/. ISSN 0798-1015. 